\title{
The Mediating Roles of Acceptance and Cognitive Reappraisal in the Relation Between Hope and Posttraumatic Growth Among Adolescents After the Ya'an Earthquake
}

\author{
Xiao Zhou ${ }^{1}$ and Xinchun $\mathrm{Wu}^{2}$ \\ ${ }^{1}$ Department of Psychology and Behavioral Sciences, Zhejiang University, Hangzhou, China \\ 2 Beijing Key Laboratory of Applied Experimental Psychology, National Demonstration Center for Experimental Psychology \\ Education, Faculty of Psychology, Beijing Normal University, Beijing, China
}

\begin{abstract}
Prev revious theoretical research has indicated that hope, cognitive reappraisal, and acceptance may contribute to posttraumatic growth (PTG). However, the combined effects of these factors on PTG have not yet been evaluated. Therefore, the current study examined the mediating roles of cognitive reappraisal and acceptance in the relationship between hope and PTG among Chinese adolescents following the Ya'an earthquake. The sample included 397 adolescent survivors, who completed selfreport measures 2.5 years after the earthquake. The mediating effects were assessed by constructing a multiple indirect effects model. The findings indicated that traumatic exposure only have predictive value for PTG, but not other variables. Moreover, when we controlled for gender, age, and traumatic exposure, hope had a direct and positive effect on PTG. We found an indirect and positive effect of hope on PTG via cognitive reappraisal and acceptance, as well as via an indirect path from cognitive reappraisal to acceptance. These findings suggest that utilising the mediating roles of cognitive reappraisal and acceptance in the relationship between hope and PTG is crucial in developing methods for fostering PTG.
\end{abstract}

Keywords: hope, cognitive reappraisal, acceptance, posttraumatic growth, PTG

\begin{abstract}
Although previous studies of trauma have revealed that many people with traumatic experiences exhibit negative psychological outcomes, some positive psychological changes have also been reported posttrauma, including improvements in personal strength, relationships, and appreciation of life (e.g., Ying, Wang, Lin, \& Chen, 2016; Yoshida et al., 2016). Tedeschi and Calhoun (1996) coined the term posttraumatic growth (PTG) to describe positive changes exhibited after struggling with traumatic events. PTG has recently attracted increasing research interest (e.g., García, Páez-Rovira, Zurtia, Martel, \& Reyes, 2014; Yuen, Ho, \& Chan, 2014). In some studies, PTG has been considered a transcendent state compared with the pretrauma state (e.g., Zoellner \& Maercker, 2006). Importantly, PTG is reported to be prevalent among survivors of various traumatic experiences (e.g., Cho \& Park, 2013; Kira et al., 2013).
\end{abstract}

To elucidate the underlying mechanisms of PTG development, some researchers have focused on potential predictive factors (e.g., Achterhof et al., 2017; García et al., 2014; Wu, Zhou, Wu, \& An, 2015), reporting that hope is a significant predictive factor for PTG (e.g., Zhou, Wu, \& Zhen, 2018). Similarly, other trauma-related studies have also indicated that hope for life predicted increased PTG (e.g., Casellas-Grau, Ochoa, \& Ruini, 2017; Heidarzadeh, Dadkhah, \& Gholchin, 2016; Yuen et al., 2014). Janoff-Bulmans' (2010) shattered assumptions theory has been an important framework for interpreting this phenomenon. In this theoretical model, it is assumed that traumatic experiences can challenge people's stable view of the world, others, and self. In turn, this can lead people to lose the sense of predictability and control of the self, others, or the world. People may then lose hope and feel a sense of hopelessness toward life (e.g., Glass, Flory, 
Hankin, Kloos, \& Turecki, 2009; Zhou, Wu, \& Wang, 2017), which can prevent the survivors of traumatic events from adopting positive strategies for coping with traumatic events and posttraumatic reactions, limiting the realisation of PTG (e.g., Ho et al., 2011). In contrast, hope may shift individuals' focus from negative events or emotional states (Scheier \& Carver, 1985), and facilitate their ability to overcome stressful life situations by engaging coping behaviour and adaptive problem solving (Reff, Kwon, \& Campbell, 2005). A study of adolescents following an earthquake revealed that once they developed a sense of hope about their posttraumatic lives, they actively sought for positive and effective strategies to struggle with traumatic events, and reconstructed their understanding of the posttraumatic self, others, and the world, ultimately leading to the realisation of PTG (Zhou, Wu, Wang, \& Tian, 2017).

Nevertheless, the predictive mechanisms of hope in relation to PTG remain unclear. However, relevant theories suggest that hope can promote PTG via other factors (e.g., Joseph \& Linley, 2005; Snyder, 2002), among which cognitive reappraisal and acceptance may be two important mediating factors. Therefore, the current study sought to further explore the potential mediating effects of cognitive reappraisal and acceptance in the relationship between hope and PTG.

Cognitive reappraisal is an antecedent-focused coping strategy (e.g., Gross, 2002), by which a person makes active efforts to repair a negative emotional state, as well as generating benign or positive interpretations or perspectives in relation to a stressful situation (e.g., Gross, 1998). According to Snyder's (2002) hope theory, hope is comprised of agency thinking and pathways thinking, and can enable people to adopt positive and functional strategies to realise their purpose. Cognitive reappraisal is among these strategies. Through cognitive reappraisal, traumatised people with a sense of hope may change their negative emotional states and thoughts regarding traumatic events (e.g., Benzein \& Berg, 2005), shifting their focus from the negative aspects of trauma to its positive side (e.g., Nes \& Segerstrom, 2006). In turn, this may enable people to make sense of the traumatic event and understand its meaning in their life, ultimately realising PTG (e.g., Zhou et al., 2015).

Acceptance of the posttrauma world may be a further important factor in the relationship between hope and PTG. Joseph and Linley's (2005) organismic valuing theory of PTG suggests that people have an innate tendency to know their own optimal life direction. This may activate one's aspiration or hope in the pursuit of fulfillment (e.g., Ryan, 1995). Particularly after the experience of trauma, hope can help traumatised individuals to accommodate new trauma-related information within an existing model of the world (e.g., Joseph \& Linley, 2005). Here, successful accommodation implies people's acceptance of reality (e.g., McCracken, 1998). Moreover, this acceptance requires people to change their previously held views of the self, others, and the world (e.g., Janoff-Bulman, 2010), which can relieve their negative psychological responses (e.g., Åkerblom, Perrin, Fischer, \& McCracken, 2015), and increase the likelihood of experiencing positive changes (e.g., Baranoff, Hanrahan, Kapur, \& Connor, 2013) and posttraumatic adjustments (e.g., Hayes, Luoma, Bond, Masuda, \& Lillis, 2006), leading to the realisation of PTG.

Although cognitive reappraisal and acceptance may separately mediate the relationship between hope and PTG, their combined effects are currently unclear. According to the organismic valuing theory of PTG (Joseph \& Linley, 2005), traumatic events can lead to a disparity between new trauma-related information and pre-existing expectations or beliefs (e.g., Janoff-Bulman, 2010). This disparity may prompt people to deal with this new information, such as seeking to understand the event retrospectively (e.g., Janoff-Bulman, 2010; Zhou, Wu, Fu, \& An, 2015) through cognitive reappraisal. Once the comprehension of traumatic information is achieved, people can then accommodate (e.g., Joseph \& Linley, 2005) and accept the posttraumatic reality, and in turn enhance their understanding of the traumatic world. Thus, it is likely that cognitive reappraisal can lead to the realisation of PTG by fostering increased acceptance.

Although several theoretical models have been proposed to describe the relationship between hope and PTG, the predictive utility of such a relationship has not been evaluated in adolescent survivors after natural disasters. Because adolescents are more susceptible to the impacts of disasters (e.g., Margolin, Ramos, \& Guran, 2010), this is a particularly important issue. However, the combined role of cognitive reappraisal and acceptance in the relationship between hope and PTG has not yet been evaluated in trauma-related studies. Importantly, adolescents' cognitive capacity is not fully developed, meaning that trauma is more likely to have event-related cognitive effects, which may have an impact on the later development of psychosomatic responses. Therefore, studies of the mechanisms by which adolescents cope with trauma constitute are urgently needed to develop methods for promoting adolescent posttrauma adjustment.

Given this background, the aim of the present study was to examine the mediating role of cognitive reappraisal and acceptance in the relationship between hope and PTG. We sought to test the following three hypotheses: (1) hope exerts a direct and positive effect on PTG; (2) cognitive reappraisal and acceptance separately mediate the relationship between hope and PTG; and (3) acceptance mediates the relationship between cognitive reappraisal and PTG.

\section{Methods}

\section{Participants and Procedures}

The present study was conducted 2.5 years after the Ya'an earthquake in Lushan county in Sichuan province, which was the most severely affected area. We first contacted the 
local education authority and informed them of the aims and methods of the study, and indicated that we could provide psychological services if required by the respondents. With the approval of the local education authority, we focused on the only two schools in Lushan county. Under the approval of head teachers and with the help of psychological teachers, students from six classes in each school were ultimately selected to participate into our investigation. All students in the selected classes were attending school on the assessment date, and the assessment was conducted under the supervision of trained individuals with a master's degree in psychology. In the present study, we selected a total of 397 adolescent survivors. The mean age of the participants was $16.42(S D=1.76)$ years, and the age range was 13 to 20 years. Of the 397 participants, $154(38.8 \%)$ were male and 242 (61.0\%) were female; one participant did not report their gender. All participants experienced this traumatic event; $9.8 \%$ of the participants were trapped and $9.1 \%$ were physically injured during the earthquake.

The study was approved by the Research Ethics Committee of Beijing Normal University and conducted with the permission of the principals of the participating schools. In the selected classes, everyone who attended school on the date of the survey was recruited to participate. There were no exclusion criteria, and compensation was not provided. The purpose of the study and the voluntary nature of the students' participation were highlighted before the survey was conducted, and written informed consent was obtained from school principals and classroom teachers.

\section{Measures}

Trauma exposure. The Traumatic Exposure Questionnaire, with 18 items (Wu, Zhang, Lin, \& Zang, 2013), was used to assess the severity of earthquake exposure among adolescents. The one-factor questionnaire has 18 items, and each of the items in this questionnaire was rated on a 3-point scale, in which 3 represented experience myself, 2 represented know of others' experience and 1 represented do not experience. This questionnaire has previously been found to have good reliability among adolescents who experienced the Ya'an earthquake (Zhou, Wu, \& Zhen, 2017). In the current study, the questionnaire exhibited good validity $\left(\chi^{2} / d f=2.57, \mathrm{CFI}=0.93\right.$, TLI $=0.90$, $\operatorname{RMSEA}(90 \% \mathrm{CI})=0.063[0.053,0.073]$, SRMR $=0.070)$ and reliability (Cronbach's $\alpha=0.79$ ).

Hope. The State Hope Scale (SHS; Snyder et al., 1996) was used to assess adolescents' sense of hope. The SHS has six items, including two dimensions: agency thinking (e.g., 'I try my best to pursue my own goals') and pathways thinking (e.g., 'I can think of many paths to realise my goals'). Each of these items was rated on an 8-point scale ranging from 1 (completely disagree) to 8 (completely agree). When using this scale, we translated the original English version of the scale into Chinese and reworded some items to clarify their meaning. In the current study, SHS exhibited good validity $\left(\chi^{2} / d f=2.53, \mathrm{CFI}=0.99\right.$, $\mathrm{TLI}=0.98$, RMSEA $(90 \% \mathrm{CI})=0.062[0.013,0.111]$, SRMR $=0.014)$ and reliability (Cronbach's $\alpha=0.85$ ).

Cognitive reappraisal. The cognitive reappraisal subscale of the Emotion Regulation Questionnaire (revised Chinese version; Wang, Liu, Li, \& Du, 2007) was used to assess cognitive reappraisal. The Emotion Regulation Questionnaire has 10 items divided into two dimensions: cognitive reappraisal and expressive suppression. Every item was rated on a 7-point Likert scale, in which 1 represented completely disagree and 7 represented completely agree. In this study, the reliability of the questionnaire was good $(\alpha=0.80)$, and it showed good validity $\left(\chi^{2} / d f=3.50\right.$, $\mathrm{CFI}=0.94$, TLI $=0.91$, RMSEA $[90 \% \mathrm{CI}]=0.079$ $[0.063,0.096]$, SRMR $=0.041)$. For the current study, we only used the cognitive reappraisal subscale, which showed good internal reliability (Cronbach's $\alpha=0.82$ ).

Acceptance. We used the acceptance subscale of the Cognitive Emotion Regulation Questionnaire (Chinese revised version; Zhu, Luo, Yao, Auerbach, \& Abela, 2007). The Cognitive Emotion Regulation Questionnaire is a 36item instrument designed to measure the following cognitive coping strategies: acceptance, positive reappraisal, self-blame, positive refocusing, rumination, catastrophising, refocus on planning, others-blame, and putting into perspective (e.g., Garnefski, Teerds, Kraaij, Legerstee, \& van den Kommer, 2004). All of these items were rated on a 5-point Likert scale, which ranged from 0 (completely disagree) to 4 (completely agree). The Chinese version of this questionnaire has been found to have good stability and reliability (e.g., Zhu et al., 2007). The current study revealed that the questionnaire had good internal reliability (Cronbach's $\alpha=0.92$ ) and acceptable validity $\left(\chi^{2} / d f=2.29, \mathrm{CFI}=0.90\right.$, TLI $=0.89$, RMSEA [ $90 \%$ $\mathrm{CI}]=0.057[0.053,0.061], \mathrm{SRMR}=0.059)$. In the current study, we selected the acceptance subscale (e.g., 'I have to accept reality'), which exhibited good internal reliability (Cronbach's $\alpha=0.75$ ).

Posttraumatic growth. A modified version of the PostTraumatic Growth Inventory (Zhou, Wu, An, Chen, \& Long, 2014) was used to assess adolescents' PTG. The modified PTGI consisted of 22 items, and included three dimensions: perceived changes in self, a changed sense of relationships with others, and a changed philosophy of life. All the items were scored on a 6-point scale, in which 0 represented no change and 5 represented very great degree of change. The score range of this questionnaire was $0-110$. This questionnaire has been found to have good stability and reliability for Chinese adolescents after experiencing an earthquake (e.g., Zhou, Wu, An, Chen, \& Long, 2014). In the current study, we found that the reliability of the inventory was good (Cronbach's $\alpha=0.89$ ) and the validity was acceptable $\left(\chi^{2} / d f=3.53, \mathrm{CFI}=0.90\right.$, TLI $=0.89$, RMSEA $[90 \% \mathrm{CI}]=0.080[0.073,0.086], \mathrm{SRMR}=0.052)$. 


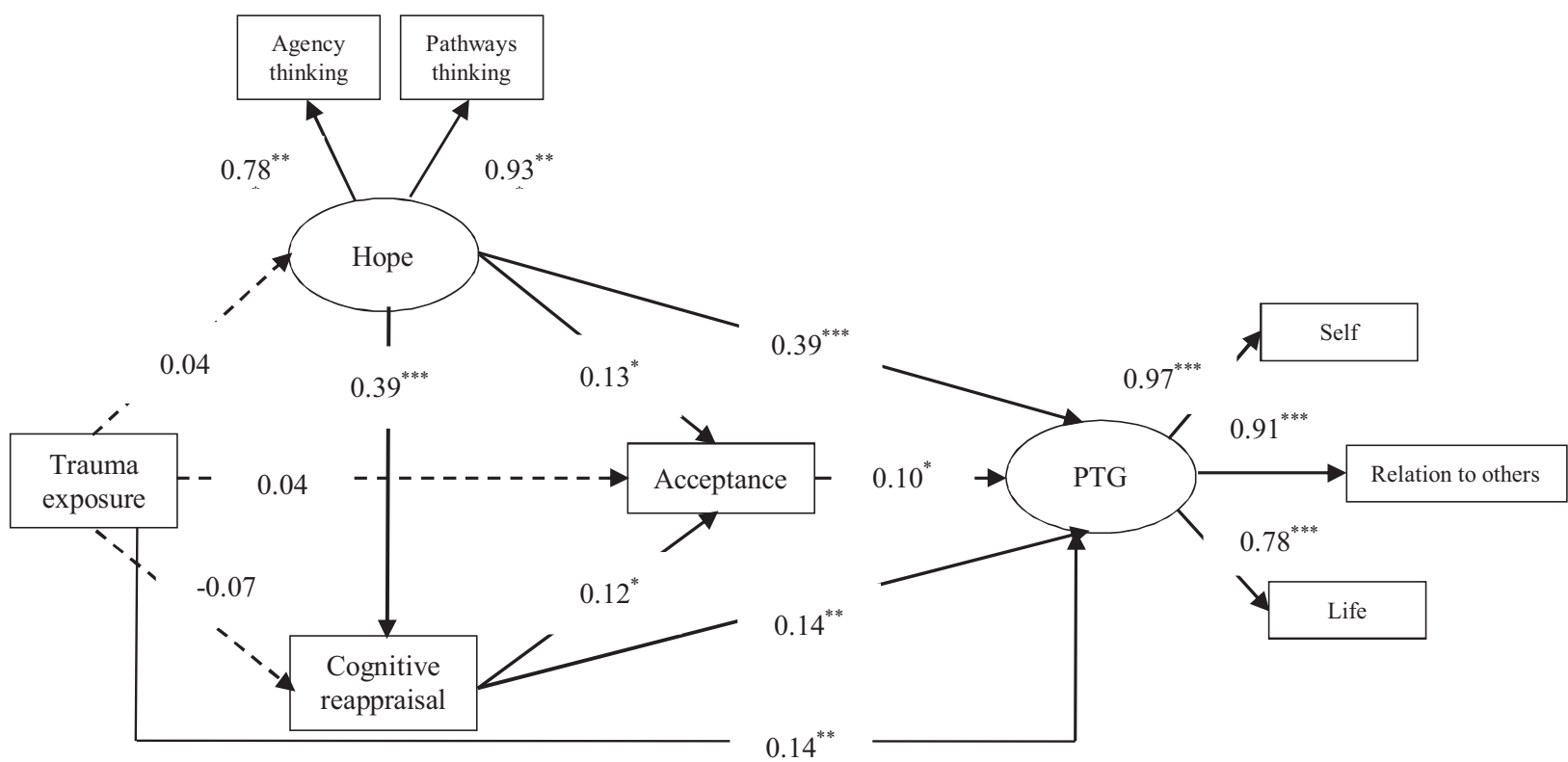

\section{Figure 1}

The multiple indirect effects model after controlling gender and age.

Note: rectangle $=$ observable variable, ellipse $=$ latent variable. Self $=$ perceived changes in self; Relation to others $=$ changed sense of relationships with others; Life = changed philosophy of life

${ }^{*} p<.05,{ }^{* *} p<.01,{ }^{* * *} p<.001$.

\section{Data Analysis Strategies}

Descriptive analyses and Pearson's correlations were first calculated to examine all the main measurements and their associations, respectively. Mplus 6.0 software (e.g., Muthén \& Muthén, 2010) was used to conduct data analysis. We first conducted an analysis of missing data on variables and found that missing data across all items were less than $2.3 \%$. We then adopted Little's Missing Completely at Random test to assess the missing data, and found that the data were missing at random, $\chi^{2}(35)=45.59, p=.108$. Maximum likelihood (ML) was then used to handle missing data.

As all the data were from the self-reported scales, to avoid possible contamination of common method bias in the study results, we balanced the item order and anonymised the measurement process. In addition, we used Harman's one-factor test (Podsakoff, Mackenzie, Lee, \& Podsakoff, 2003) to assess bias. Eight factors with eigenvalues greater than 1 were extracted. These factors explained $65.88 \%$ of the variance. Nevertheless, the first factor accounted for $29.91 \%$ of the variance, which is less than $40 \%$ of the variance. These results indicated that there was no significant common method variance in this study.

Next, we constructed two models to examine our research questions: (1) a direct effects model of the structural path from hope to PTG; and (2) based on the direct model, we inserted mediators (e.g., acceptance and cognitive reappraisal) between hope and PTG, and added a predictive path from cognitive reappraisal to acceptance, establishing a multiple indirect effects model (see Figure 1). Additionally, considering the importance of traumatic exposure in the development of PTG, we controlled for traumatic exposure in the model for examining the effects of hope, acceptance and cognitive reappraisal on PTG. Lastly, bootstrap method was used to examine the indirect effects.

\section{Results}

\section{Descriptive Statistics and Correlation Analysis}

Table 1 shows the results of descriptive statistics and correlation analysis. The mean levels of trauma exposure, hope, acceptance, cognitive reappraisal, and PTG were $20.45,29.25,10.15,28.42$, and 62.69 respectively. Pearson's correlations were also calculated, revealing that gender had significant relationships with hope, cognitive reappraisal, and PTG. Age was non-significantly associated with other variables. Traumatic exposure was only related significantly to PTG, but not other factors. There were positive correlations between hope, acceptance, cognitive reappraisal, and PTG.

\section{Analysis of Mediating Effects}

We followed two steps to examine the mediating effects of acceptance and cognitive reappraisal in the relationship between hope and PTG. The first was to examine the direct effects model with the path from hope to PTG, and the second was to assess the multiple indirect effects model of hope, acceptance, cognitive reappraisal, and PTG.

A direct effects model was first constructed to examine the direct effects of hope on PTG. The results revealed that the model fit the data well $\left(\chi^{2} / d f=2.02, \mathrm{CFI}=0.996\right.$, $\mathrm{TLI}=0.991$, RMSEA $(90 \% \mathrm{CI})=0.054[0.000,0.104]$, 
Table 1

Means, Standard Deviations, and Correlations Among Main Variables

\begin{tabular}{|c|c|c|c|c|c|c|c|}
\hline & $M \pm S D$ & 1 & 2 & 3 & 4 & 5 & 6 \\
\hline 1. Gender & - & 1.00 & & & & & \\
\hline 2. Age & $16.42 \pm 1.76$ & 0.02 & 1.00 & & & & \\
\hline 3. Trauma exposure & $20.45 \pm 3.22$ & -0.01 & 0.07 & 1.00 & & & \\
\hline 4. Hope & $29.25 \pm 7.94$ & $-0.12^{*}$ & -0.06 & 0.03 & 1.00 & & \\
\hline 5. Acceptance & $10.15 \pm 3.23$ & 0.01 & 0.04 & 0.04 & $0.16^{* *}$ & 1.00 & \\
\hline 6. Cognitive reappraisal & $28.42 \pm 6.01$ & $0.19^{* * *}$ & 0.06 & -0.06 & $0.32^{* * *}$ & $0.16^{* *}$ & 1.00 \\
\hline 7. PTG & $62.69 \pm 20.90$ & $0.15^{*}$ & 0.06 & $0.16^{* *}$ & $0.38^{* * *}$ & $0.21^{* * *}$ & $0.31^{* * *}$ \\
\hline
\end{tabular}

Note: Gender was coded as 1 and 2 in this study, and 1 represents male, and 2 represents female. $* p<.05, * * p<.01, * * * p<.001$.

SRMR $=0.012$ ), and that hope had a direct and positive effect on PTG.

Next, after controlling for gender, age, and traumatic exposure, we inserted the mediators (acceptance and cognitive reappraisal) between hope and PTG, and added a predictive path from cognitive reappraisal to acceptance to establish a multiple indirect effects model (see Figure 1). This model fit the data well $\left(\chi^{2} / d f=1.12, \mathrm{CFI}=0.998\right.$, $\mathrm{TLI}=0.996$, RMSEA $(90 \% \mathrm{CI})=0.017[0.000,0.049]$, SRMR $=0.015)$. Path analyses revealed that after controlling the gender and age, traumatic exposure had no significant effect on hope, cognitive reappraisal, or acceptance, but had a significant and positive effect on PTG. Hope had a significant and positive effect on acceptance and cognitive reappraisal, as well as on PTG. Cognitive reappraisal had a significant and positive effect on acceptance and PTG. Acceptance positively predicted PTG. Taken together, all of the variables in this model explained $30 \%$ of the variance of PTG. These results indicated that when age, gender, and traumatic exposure were controlled for, hope not only had a direct and positive effect on PTG, but also indirectly affected PTG through acceptance and cognitive reappraisal, as well as through a multiple path from cognitive reappraisal to acceptance. Then, the bootstrap method was used to examine the indirect effects, and the results indicated that the indirect effects value from cognitive reappraisal and acceptance was 0.05 and 0.01 , respectively. The multiple indirect effect value from cognitive reappraisal to acceptance is 0.005 . The indirect effect accounts for $16.7 \%$ of the total effect hope predicted PTG.

\section{Discussion}

The current study examined the combined roles of hope, cognitive reappraisal, and acceptance in PTG among adolescents after natural disasters. The results revealed that exposure to trauma had a non-significant effect on hope, cognitive reappraisal, and acceptance, but had a positive effect on PTG. Additionally, we found that hope not only exerted a direct and positive impact on PTG, but also could serve as a stimulus for the realisation of PTG through cognitive reappraisal or acceptance.

Specifically, the finding that traumatic exposure only affected PTG may be related to the time since trauma (e.g.,
Meyerson, Grant, Carter, \& Kilmer, 2011). Several studies have reported that a longer time since trauma is associated with a reduction in the negative effects of traumatic events (e.g., Wolchik, Coxe, Tein, Sandler, \& Ayers, 2009). Therefore, with the time that had elapsed since the Ya'an earthquake, adolescents may have overcome the negative effects of the earthquake, meaning that their hope, cognitive reappraisal, and acceptance were less influenced. Thus, the time since trauma may moderate the negative effects of trauma (e.g., Helgeson, Reynolds, \& Tomich, 2006), possibly giving people more time to positively rethink trauma-related information and emotions (e.g., Meyerson et al., 2011), increasing the likelihood of experiencing positive changes and ultimately realizing PTG.

Hope was found to have a direct and positive effect on PTG, which is consistent with $\mathrm{H} 1$ and the findings of several previous studies (e.g., Casellas-Grau et al., 2017; Heidarzadeh et al., 2016; Yuen et al., 2014; Zhou et al., 2018). Other studies have reported that individuals with hope have been found to exhibit a positive attitude towards the posttraumatic self, others and the world (e.g., Galindo, 2016; Zhou et al., 2018). In turn, this attitude has been found to distract attention from the negative results following stressful events (e.g., Scheier \& Carver, 1985), and promote the adoption of positive strategies to cope with trauma (e.g., Nes \& Segerstrom, 2006), gradually realising PTG.

Importantly, when we controlled for age, gender, and traumatic exposure, we found that adolescents with hope were able to realise PTG through their cognitive reappraisal of traumatic events, which is consistent with the first part of H2, and supports Snyder's (2002) hope theory. For adolescents who have experienced disasters, high levels of hope can help build confidence in coping with trauma (e.g., Singh \& Jha, 2013), which can further help adolescents to positively rethink their traumatic experience, as well as the self, others, and the world after trauma (e.g., Benzein \& Berg, 2005; Zhou et al., 2017; Zhou et al., 2018). This process would be expected to be beneficial in reconstructing the meaning of the posttraumatic world, as well as realising PTG (e.g., Calhoun, Cann, \& Tedeschi, 2010). The second part of $\mathrm{H} 2$ was also supported by the current findings that hope could indirectly and positively predict PTG by acceptance. One possible explanation is that hope 
can be considered as a motivational factor, encouraging adolescents to accommodate new trauma-related information within their existing models of the world (e.g., Joseph \& Linley, 2005). This notion suggests that adolescents may accept the current self or the current circumstances when this type of information accommodation is successful, and that acceptance leads to final adjustment following trauma, and the realisation of PTG.

In addition, the current findings also suggested that hope exerted an indirect and significant effect on PTG through acceptance via cognitive reappraisal, which is consistent with $\mathrm{H} 3$ and supports the PTG theory of Joseph and Linley (2005). Adolescents with hope have been found to exhibit positive attitudes and beliefs in relation to the posttraumatic world, prompting them to rethink the disparity in their pretrauma and posttrauma worldviews (e.g., Janoff-Bulman, 2010) and to reconstruct their comprehension of the posttraumatic world. To achieve a new sense of cognitive balance, adolescents may then change their existing worldviews to accommodate and accept new trauma-related information, and attempt to understand the significance of self, others, and the world following trauma (e.g., Joseph \& Linley, 2005), thereby realising PTG.

The current study involved several limitations that should be acknowledged. First, although we discussed the role of time since trauma in accounting for the effects of trauma as a controllable variable, the cross-sectional design of the current study limited further investigation into the effects of time since trauma. Besides, it is difficult to determine the causal relations between variables, so future research could adopt a longitudinal research design to examine the causal relations between hope, acceptance, cognitive reappraisal, and PTG. Additionally, the current study lacked a control group, making it difficult to exclude the potential effects of other socio-demographic characteristics. Moreover, other than gender and age, this study did not take other socio-demographic characteristics (e.g., socioeconomic status, parental education) into consideration, although such variables may also play a role in PTG.

Despite these limiations, the current study further supports Joseph and Linley's (2005) organismic valuing theory of PTG and Snyder's (2002) hope theory, indicating that hope could not only exert a direct and positive effect on PTG, but could also lead to PTG through cognitive reappraisal or acceptance. Regarding clinical implications, the current findings suggest that efforts should focus on helping adolescents to foster a sense of hope. Specifically, psychologists and educators could carry out targeted education focused on hope. For instance, creating warmer school and class environments increases the probability that students perceive positive experiences, and providing proper encouragement can aid them to develop a sense of accomplishment. In such ways, their internal locus of control and their desire to progress (e.g., Galindo, 2016), and then their feelings of hope toward the posttraumatic self, others, and the world will be also improved. In addi- tion, through group or individual counselling, psychologists and educators can inspire students to establish their goals and strengthen their pathways thoughts to improve their sense of hope. Adolescents' increased hope then contributes to form a positive attitude in relation to trauma, which helps them to accept the posttraumatic world, and finally mitigates the negative effects of trauma and advances their positive growth after trauma.

\section{Funding}

This study was supported by the Major Project of Beijing Social Science Fund, China (grant number: 15ZDA11)

\section{References}

Achterhof, R., Dorahy, M.J., Rowlands, A., Renouf, C., Britt, E., \& Carter, J.D. (2017). Predictors of posttraumatic growth 10-11 months after a fatal earthquake. Psychological Trauma Theory Research Practice \& Policy, 10, 208-215.

Åkerblom, S., Perrin, S., Fischer, M.R., \& McCracken, L.M. (2015). The mediating role of acceptance in multidisciplinary cognitive-behavioral therapy for chronic pain. Journal of Pain, 16, 606-615.

Baranoff, J., Hanrahan, S.J., Kapur, D., \& Connor, J.P. (2013). Acceptance as a process variable in relation to catastrophizing in multidisciplinary pain treatment. European Journal of Pain, 17, 101-110.

Benzein, E.G., \& Berg, A.C. (2005). The level of and relation between hope, hopelessness and fatigue in patients and family members in palliative care. Palliative Medicine, 19, 234-240.

Calhoun, L.G., Cann, A., \& Tedeschi, R.G. (2010). The posttraumatic growth model: Socio-cultural considerations. In T. Weiss \& R. Berger (Eds.), Posttraumatic growth and culturally competent practice: Lessons learned from around the globe (pp. 1-14). Hoboken, NJ: Wiley.

Casellas-Grau, A., Ochoa, C., \& Ruini, C. (2017). Psychological and clinical correlates of posttraumatic growth in cancer: A systematic and critical review. Psycho-Oncology, 26, 20072018.

Cho, D., \& Park, C.L. (2013). Growth following trauma: Overview and current status. Terapia Psicologica, 31, 69-79.

Galindo, D.L. (2016). Trauma, resilience, hope, and religious coping in Haiti (Unpublished doctoral thesis). George Fox University, Newberg, OR.

García, F.E., Páez-Rovira, D., Zurtia, G.C., Martel, H.N., \& Reyes, A.R. (2014). Religious coping, social support and subjective severity as predictors of posttraumatic growth in people affected by the earthquake in Chile on 27/2/2010. Religions, 5, 1132-1145.

Garnefski, N., Teerds, J., Kraaij, V., Legerstee, J., \& van den Kommer, T. (2004). Cognitive emotion regulation strategies and depressive symptoms: Differences between males and females. Personality and Individual Differences, 36, 267276.

Glass, K., Flory, K., Hankin, B.L., Kloos, B., \& Turecki, G. (2009). Are coping strategies, social support, and hope associated 
with psychological distress among Hurricane Katrina survivors? Journal of Social and Clinical Psychology, 28, 779795.

Gross, J.J. (1998). Antecedent-and response-focused emotion regulation: Divergent consequences for experience, expression, and physiology. Journal of Personality and Social Psychology, 74, 224-237.

Gross, J.J. (2002). Emotion regulation: Affective, cognitive, and social consequences. Psychophysiology, 39, 281-291.

Hayes, S.C., Luoma, J.B., Bond, F.W., Masuda, A., \& Lillis, J. (2006). Acceptance and commitment therapy: Model, processes and outcomes. Behaviour Research and Therapy, 44, $1-25$.

Helgeson, V.S., Reynolds, K.A., \& Tomich, P.L. (2006). A metaanalytic review of benefit finding and growth. Journal of Consulting and Clinical Psychology, 74, 797-816.

Heidarzadeh, M., Dadkhah, B., \& Gholchin, M. (2016). Posttraumatic growth, hope, and depression in elderly cancer patients. International Journal of Medical Research \& Health Sciences, 5, 455-461.

Ho, S., Rajandram, R.K., Chan, N., Samman, N., McGrath, C., \& Zwahlen, R.A. (2011). The roles of hope and optimism on posttraumatic growth in oral cavity cancer patients. Oral Oncology, 47, 121-124.

Janoff-Bulman, R. (2010). Shattered assumptions. New York, NY: Simon and Schuster.

Joseph, S., \& Linley, P.A. (2005). Positive adjustment to threatening events: An organismic valuing theory of growth through adversity. Review of General Psychology, 9, 262-280.

Kira, I.A., Aboumediene, S., Ashby, J.S., Odenat, L., Mohanesh, J., \& Alamia, H. (2013). The dynamics of posttraumatic growth across different trauma types in a Palestinian sample. Journal of Loss and Trauma, 18, 120-139.

Margolin, G., Ramos, M.C., \& Guran, E.L. (2010). Earthquakes and children: The role of psychologists with families and communities. Professional Psychology: Research and Practice, 41, 1-9.

McCracken, L.M. (1998). Learning to live with the pain: Acceptance of pain predicts adjustment in persons with chronic pain. Pain, 74, 21-27.

Meyerson, D.A., Grant, K.E., Carter, J.S., \& Kilmer, R.P. (2011). Posttraumatic growth among children and adolescents: A systematic review. Clinical Psychology Review, 31, 949-964.

Muthén, B.O., \& Muthén, L.K. (2010). Mplus (version 6.00)[computer software]. Los Angeles, CA: Author.

Nes, L.S., \& Segerstrom, S.C. (2006). Dispositional optimism and coping: A meta-analytic review. Personality and Social Psychology Review, 10, 235-251.

Podsakoff, P.M., Mackenzie, S.B., Lee, J.Y., \& Podsakoff, N.P. (2003). Common method biases in behavioral research: A critical review of the literature and recommended remedies. Journal of Applied Psychology, 88, 879-903.

Reff, R.C., Kwon, P., \& Campbell, D.G. (2005). Dysphoric responses to a naturalistic stressor: Interactive effects of hope and defense style. Journal of Social \& Clinical Psychology, 24, 638-648.
Ryan, R.M. (1995). Psychological needs and the facilitation of integrative processes. Journal of Personality, 63, 397-427.

Scheier, M.F., \& Carver, C.S. (1985). Optimism, coping, and health: Assessment and implications of generalized outcome expectancies. Health Psychology, 4, 219-247.

Singh, I., \& Jha, A. (2013). Anxiety, optimism and academic achievement among students of private medical and engineering colleges: A comparative study. Journal of Educational and Developmental Psychology, 3, 222-233.

Snyder, C.R. (2002). Hope theory: Rainbows in the mind. Psychological Inquiry, 13, 249-275.

Snyder, C.R., Sympson, S.C., Ybasco, F.C., Borders, T.F., Babyak, M.A., \& Higgins, R.L. (1996). Development and validation of the State Hope Scale. Journal of Personality and Social Psychology, 70, 321-335.

Tedeschi, R.G., \& Calhoun, L.G. (1996). The Posttraumatic Growth Inventory: Measuring the positive legacy of trauma. Journal of Traumatic Stress, 9, 455-471.

Wang, L., Liu, H., Li, Z., \& Du, W. (2007). Reliability and validity of Emotion Regulation Questionnaire Chinnese revised version. China Journal of Health Psychology, 15, 503-505.

Wolchik, S.A., Coxe, S., Tein, J.Y., Sandler, I.N., \& Ayers, T.S. (2009). Six-year longitudinal predictors of posttraumatic growth in parentally bereaved adolescents and young adults. Journal of Death and Dying, 58, 107-128.

Wu, X., Zhang, Y., Lin, C., \& Zang, W. (2013). The effect of disaster exposure on PTSD of primary and secondary students: Mediating and moderating effect [in Chinese]. Psychological Development and Education, 29, 641-648.

Wu, X., Zhou, X., Wu, Y., \& An, Y. (2015). The role of rumination in posttraumatic stress disorder and posttraumatic growth among adolescents after the Wenchuan earthquake. Frontiers in Psychology, 6, 1335.

Ying, L., Wang, Y., Lin, C., \& Chen, C. (2016). Trait resilience moderated the relationships between PTG and adolescent academic burnout in a post-disaster context. Personality and Individual Differences, 90, 108-112.

Yoshida, H., Kobayashi, N., Honda, N., Matsuoka, H., Yamaguchi, T., Homma, H., \& Tomita, H. (2016). Posttraumatic growth of children affected by the great east japan earthquake and their attitudes to memorial services and media coverage. Psychiatry \& Clinical Neurosciences, 70, 193201.

Yuen, A.N.Y., Ho, S.M.Y., \& Chan, C.K.Y. (2014). The mediating roles of cancer-related rumination in the relationship between dispositional hope and psychological outcomes among childhood cancer survivors. Psycho-Oncology, 23, 412-419.

Zhou, X., Wu, X., An, Y., Chen, H., \& Long, C. (2014). Social support mediate the associations between gratitude and post-traumatic growth in middle school students at three years after Wenchuan earthquake [in Chinese]. Psychological Development and Education, 30, 68-74.

Zhou, X., Wu, X., Fu, F., \& An, Y. (2015). Core belief challenge and rumination as predictors of PTSD and PTG among adolescent survivors of the Wenchuan earthquake. 
Psychological Trauma Theory Research Practice \& Policy, 7, 391-397.

Zhou, X., Wu, X., Wang, W., \& Tian, Y. (2017). The relationship between social support and posttraumatic growth: The mediated role of state hope and positive reappraisal. Psychological Development and Education, 33, 587-594.

Zhou, X., Wu, X., \& Wang, W. (2017). The roles of hope and rumination in the relationship between optimism and posttraumatic growth among adolescents after Ya'an earthquake. Psychological Development and Education, 33, 328-336.

Zhou, X., Wu, X., \& Zhen, R. (2017). Understanding the relationship between social support and posttraumatic stress disorder/posttraumatic growth among adolescents after Ya'an earthquake: The role of emotion regulation. Psychologi- cal Trauma: Theory, Research, Practice, and Policy, 9, 214221

Zhou, X., Wu, X., \& Zhen, R. (2018). Self-esteem and hope mediate the relations between social support and post-traumatic stress disorder and growth in adolescents following the Ya'an earthquake. Anxiety Stress \& Coping, 31, 32-45.

Zhu, X., Luo, F., Yao, S., Auerbach, R.P., \& Abela, J.R.Z. (2007). Reliability and validity of the Cognitive Emotion Regulation Questionnaire - Chinese version [in Chinese]. Chinese Journal of Clinical Psychology, 15, 121-124.

Zoellner, T., \& Maercker, A. (2006). Posttraumatic growth in clinical psychology - A critical review and introduction of a two component model. Clinical Psychology Review, 26, $626-653$ 